\title{
Antibiotic prescription patterns of South African general medical practitioners for treatment of acute bronchitis
}

\author{
N B Q Ncube, ${ }^{1} \mathrm{MSc}\left(\mathrm{Med}\right.$ Sc); G C Solanki, ${ }^{2} \mathrm{DrPH} ;$ T Kredo, ${ }^{3} \mathrm{MSc} ; \mathbf{R}$ Lalloo, ${ }^{4} \mathrm{PhD}$ \\ ${ }^{1}$ School of Public Health, Faculty of Community and Health Sciences, University of the Western Cape, Cape Town, South Africa \\ ${ }^{2}$ Towers Watson, Cape Town, South Africa; and Health Economics Unit, Department of Public Health, Faculty of Health Sciences, University of \\ Cape Town, South Africa \\ ${ }^{3}$ Cochrane South Africa, South African Medical Research Council, Cape Town, South Africa \\ ${ }^{4}$ School of Dentistry, Faculty of Health Sciences, University of Queensland, Brisbane, Australia
}

Corresponding author: NB Q Ncube(nncube@uwc.ac.za)

Background. Antibiotic resistance is a significant public health problem. Prudent use of antibiotics is crucial in reducing this resistance. Acute bronchitis is a common reason for consultations with general medical practitioners, and antibiotics are often prescribed even though guidelines recommend not prescribing them for uncomplicated acute bronchitis.

Objective. To analyse the antibiotic prescription patterns of South African (SA) general medical practitioners in the treatment of acute bronchitis.

Methods. The 2013 claims for members of 11 health insurance schemes were analysed to assess antibiotic prescription patterns for patients diagnosed with acute bronchitis. The patterns were assessed by type of bronchitis, chronic health status of the patients, sex and age group. The types of antibiotic prescribed were also analysed.

Results. Of 166821 events analysed, an antibiotic was prescribed in more than half (52.9\%). There were significant differences by type of bronchitis and chronic health status. Patients with viral bronchitis were more likely to be prescribed an antibiotic than those with bacterial bronchitis (odds ratio (OR) 1.17, 95\% confidence interval (CI) 1.08 - 1.26). Patients with a chronic illness were less likely to be prescribed an antibiotic than those without (OR $0.58,95 \%$ CI 0.57 - 0.60). More than $70 \%$ of the antibiotics prescribed were cephalosporins, penicillins and other beta-lactams.

Conclusions. Prescription rates of antibiotics for acute bronchitis by SA general medical practitioners are high. There is an urgent need to follow the guidelines for antibiotic use for acute bronchitis to reduce the likelihood of increasing resistance to available antibiotics.

S Afr Med J 2017;107(2):119-122. DOI:10.7196/SAMJ.2017.v107i2.11276

While antibiotics save millions of lives globally each year, their indiscriminate use poses an increasingly serious threat to public health. ${ }^{[1]}$ The emergence of antibiotic resistance is of significant concern, with the Centers for Disease Control and Prevention having estimated that in the USA alone, at least two million illnesses and 23000 deaths are caused by antibiotic-resistant bacteria. ${ }^{[2]}$ The emergence of antibiotic-resistant bacteria adversely affects mortality, treatment costs, disease spread and duration of illness, and increases pressure on the choice of appropriate antibiotics as more first-line antibiotics are used for self-limiting conditions and bacteria become resistant to these. ${ }^{[3]}$

Acute bronchitis is a common reason for consultations with a general medical practitioner, and antibiotics are often prescribed to treat this self-limiting and usually viral condition. ${ }^{[4,5]}$ A Cochrane review highlights the fact that considerable research has been done on the effectiveness of using antibiotics in the treatment of acute bronchitis. ${ }^{[4]}$

For patients presenting with acute bronchitis, the National Institute for Health and Care Excellence (NICE) guidelines ${ }^{[6]}$ recommend that unless a patient is at high risk, a no-antibiotic prescribing strategy or a delayed antibiotic prescribing strategy should be agreed on with the patient. Based on the NICE guidelines, a patient is considered to be at high risk if he or she is systemically very unwell, has symptoms suggestive of serious illness/or complications, is at risk of complications because of pre-existing comorbidity, is a young child born prematurely, or is $>65$ years old with acute cough and two or more of the following criteria (or $>80$ years old with acute cough and one or more of the following criteria): (i) hospitalisation during the previous year; (ii) type 1 or type 2 diabetes; (iii) a history of congestive heart failure; and (iv) current use of oral glucocorticoids. For these patients, the no-antibiotic prescribing strategy and the delayed antibiotic prescribing strategy should not be considered. ${ }^{[6]}$

The South African (SA) Standard Treatment Guidelines and Essential Medicines List (SA STG/EML) ${ }^{[7]}$ for the primary healthcare level recommends that antibiotics should not be given for uncomplicated acute bronchitis, but should be considered in patients infected with HIV as they are at a high risk of developing bacterial lower respiratory tract infections. ${ }^{[7]}$ For HIV-infected patients, the guidelines recommend prescribing penicillin for 5 days, or a macrolide-like azithromycin for 3 days in penicillin-allergic patients. ${ }^{[7]}$ For all other patients, if an antibiotic is prescribed, amoxicillin or tetracycline should be the first choice, while in the case of penicillin allergy, a tetracycline or macrolide is a good alternative. $^{[8]}$ Studies from the USA show that broad-spectrum macrolides are increasingly being prescribed for acute bronchitis, and this is not an appropriate choice considering both international and local recommendations. ${ }^{[9,10]}$

While national and international guidelines for treating acute bronchitis do not recommend the use of antibiotics, ${ }^{[4,6,7,11,12]}$ more than $50 \%$ of patients are prescribed one. ${ }^{[3]} \mathrm{A}$ study summarising multistage 
probability surveys of ambulatory care in the USA reported a prescription rate of $71 \%$ between 1996 and 2010, from $60-80 \%$ between 1980 and 1999. ${ }^{[9]}$ A study in The Netherlands focusing on children reported a prescription rate of $46 \%$ for a diagnosis of acute bronchitis. ${ }^{[13]}$ In SA there is limited information on the antibiotic prescribing patterns of general medical practitioners for acute bronchitis.

\section{Objective}

The objective of this exploratory study was to analyse the antibiotic prescription patterns of SA health insurance-linked general medical practitioners treating patients with acute bronchitis, and to assess the extent to which the prescribing patterns are in alignment with evidence-informed clinical guidelines.

\section{Methods}

Approximately 8.78 million lives were covered by private health insurance (medical aid) schemes in SA in 2013. For this study, the 2013 claims for members of 11 health insurance schemes comprising 1.04 million lives (11.8\% of the insured population) were analysed. Data for the study were obtained from the data warehouse of Towers Watson, an independent consulting firm providing consulting and actuarial services to SA health insurance schemes and pension funds. The company does not advise its clients on the use of the antibiotics and therefore had no vested interest in the outcome of the study. Data for the study were made available as part of Towers Watson's commitment to support research initiatives with broader public health significance. The data were accessed in terms of and under the conditions set out in the consulting agreement between Towers Watson and their client schemes. The data were analysed by Towers Watson internally and were not made available to any other third party. All findings were presented at an aggregate level, and at no point was confidential scheme or member information disclosed.

For this study, the claims submitted to medical schemes for reimbursement of services rendered or items dispensed to members in the treatment of acute bronchitis were analysed. For each of these claims, the health provider submits a claim to the medical scheme that has at least the following information: ( $i$ ) a unique identifier for the patient being treated; (ii) the date on which the service was rendered; (iii) a unique identifier for the provider providing the services; (iv) a code and description for each service rendered/item dispensed; $(v)$ the
ICD-10 (10th revision of the International Statistical Classification of Diseases and Related Health Problems) code for the diagnosis of the condition being treated; ( $v i$ a Current Procedural Terminology (CPT) code for the procedure carried out; (vii) a National Pharmaceutical Product Index (NAPPI) code for any surgical, medical or consumable item dispensed; and (viii) the amount being claimed.

An underlying assumption of the analysis was that all the claims for a patient on the same date were related to the same 'event'. An 'event' was defined as consisting of all claims with the same service date from general practitioners and pharmacists related to the treatment of acute bronchitis for a particular patient. If the claims related to an event included any of the ICD-10 codes listed in Table 1, the event was defined as an 'acute bronchitis' event. Each acute bronchitis event was further categorised into one of three types (bacterial, viral, or unknown/ unspecified), based on the ICD-10 code categorisation as set out in Table 1. An event was considered to be positive for antibiotic prescription if there was a claim related to the event for any of the following categories of antibiotics: penicillins, fluoroquinolones, erythromycin and other macrolides, tetracyclines, and chloramphenicol. Again, the underlying assumption was that if there was an antibiotic claim and a claim for the treatment of acute bronchitis on the same day, the antibiotic claim was related to the treatment of acute bronchitis. The study was limited to analyses and claims related to the first visit for an episode of acute bronchitis. Claims related to repeat visits for the same episode (acute bronchitis events for the same patient within a 7-day period) were excluded.
The SA STG/EML guidelines ${ }^{[7]}$ recommend that antibiotics should not be given for uncomplicated acute bronchitis, except for patients co-infected with HIV. The NICE guidelines recommend a no-antibiotic or delayed prescribing strategy unless the patient is at high risk of developing complications when he or she has acute bronchitis (e.g. chronically ill patients), is $>65$ years of age and has other co-morbidities, or has been confirmed to have a bacterial infection. ${ }^{[6]}$ Given the limitations of the data available for this study, the extent to which prescribing patterns were in alignment with these clinical guidelines was assessed by analysing antibiotic prescription patterns by acute bronchitis type (bacterial, viral, unknown/unspecified), age ( $\leq 5$ years, 6 65 years, $>65$ years), gender (male, female) and medical status (chronic if the member had asthma, a cardiovascular disease, diabetes mellitus or HIV infection; non-chronic if the member did not have any of the stated conditions). Within these analytical categories, older patients ( $>65$ years) and/or patients with chronic conditions (regardless of age) were generally considered to fall into the 'high-risk' category and were expected to have higher prescription rates. Chronic status of a member was determined on the basis of ongoing medicine use by the member. A logistic regression model was used to test the adjusted statistical significance of the association between the exploratory variables (bronchitis type, gender, age group and chronic status) and the dependent variable (antibiotic prescription). Sample sizes, percentages and odds ratios (ORs) with 95\% confidence intervals (CIs) are reported, a 95\% CI excluding 1 being considered statistically significant. The type of antibiotic prescribed was also assessed by type of acute bronchitis.
Table 1. Classification of acute bronchitis types by ICD-10 code

\begin{tabular}{llll}
\hline Acute bronchitis type & $\begin{array}{l}\text { ICD } \\
\text { code }\end{array}$ & World Health Organization full description & $\%$ \\
\hline Bacterial (antibiotics & $\mathrm{J} 20.0$ & Acute bronchitis due to Mycoplasma pneumoniae & 0.6 \\
may be indicated) & $\mathrm{J} 20.1$ & Acute bronchitis due to Haemophilus influenzae & 2.3 \\
& $\mathrm{~J} 20.2$ & Acute bronchitis due to Streptococcus & 2.9 \\
Viral (antibiotics not & $\mathrm{J} 20.3$ & Acute bronchitis due to Coxsackie virus & 0.1 \\
indicated) & $\mathrm{J} 20.4$ & Acute bronchitis due to parainfluenza virus & 1.5 \\
& $\mathrm{~J} 20.5$ & Acute bronchitis due to respiratory syncytial virus & 0.3 \\
& $\mathrm{~J} 20.6$ & Acute bronchitis due to rhinovirus & 0.4 \\
Type unknown/ & $\mathrm{J} 20.7$ & Acute bronchitis due to echovirus & 0.0 \\
unspecified & $\mathrm{J} 20$ & Acute bronchitis & 0.0 \\
& $\mathrm{~J} 20.8$ & Acute bronchitis due to other specified organisms & 5.3 \\
& $\mathrm{~J} 20.9$ & Acute bronchitis; unspecified & 86.6
\end{tabular}




\section{Ethics approval}

Ethics approval for the study was granted by the University of the Western Cape's Senate Research Committee, project registration number 15/3/24.

\section{Results}

Of the 1043653 lives analysed, 48.5\% were female. By age group, $8.5 \%$ were $\leq 5$ years, $82.8 \% 6-65$ years and $8.7 \%>65$ years old. The average age was 32 years. A quarter $(24.8 \%)$ of members had a chronic condition. Thirtyfour percent of the claims for acute bronchitis were from Gauteng Province, 17.2\% from the Western Cape, $15.6 \%$ from KwaZulu-Natal, $10.4 \%$ from the Eastern Cape, $6.4 \%$ from the Free State, $6.2 \%$ from Mpumalanga, 5.0\% from the Northern Cape, $3.0 \%$ from North West and 2.1\% from Limpopo.

There were 166821 acute bronchitis events in the study population during the study period. Causative agents for acute bronchitis were determined according to the ICD-10 codes listed in Table 1. Table 2 sets out the proportions of prescription rates for acute bronchitis by type of infection, gender, age, and whether a patient had a coexisting chronic condition or not. Antibiotics were prescribed in $52.9 \%$ of the acute bronchitis events (Table 2). However, there was some variation in prescription patterns across the various analytical categories. Compared with an antibiotic prescription rate of $53.6 \%$ for bacterial events, the prescription rate for viral events was significantly higher (59.2\%; OR $1.17,95 \%$ CI $1.08-1.26$ ) and that for unknown/unspecified events significantly lower (52.7\%; OR 0.95, 95\% CI 0.91 0.99). Prescription rates for patients with a chronic condition (38.2\%) were significantly lower than those for patients without any of the specified chronic conditions (56.3\%;

Table 2. Acute bronchitis events and prescription rates

\begin{tabular}{|c|c|c|c|}
\hline & $\begin{array}{l}\text { Events, } \\
n(\%)\end{array}$ & $\begin{array}{l}\text { Antibiotic } \\
\text { prescribed, } n(\%)\end{array}$ & $\begin{array}{l}\text { Adjusted OR } \\
(95 \% \mathrm{CI})\end{array}$ \\
\hline Overall & $166821(100)$ & $88193(52.9)$ & \\
\hline \multicolumn{4}{|l|}{ Bronchitis type } \\
\hline Bacterial & $9551(5.7)$ & $5119(53.6)$ & 1 \\
\hline Viral & $3987(2.4)$ & $2360(59.2)$ & $1.17(1.08-1.26)^{\star}$ \\
\hline Unknown/unspecified & $153283(91.9)$ & $80714(52.7)$ & $0.95(0.91-0.99)^{*}$ \\
\hline \multicolumn{4}{|l|}{ Gender } \\
\hline Female & 80933 (48.5) & $41132(50.8)$ & 1 \\
\hline Male & $85888(51.5)$ & $47061(54.8)$ & $1.15(1.13-1.17)^{\star}$ \\
\hline \multicolumn{4}{|l|}{ Age group (years) } \\
\hline$\leq 5$ & $28180(16.9)$ & $16691(59.2)$ & $1.19(1.16-1.22)^{*}$ \\
\hline $6-65$ & $129268(77.5)$ & $69107(53.5)$ & 1 \\
\hline$>65$ & $9373(5.6)$ & $2395(25.6)$ & $0.41(0.39-0.43)^{*}$ \\
\hline \multicolumn{4}{|l|}{ Chronic } \\
\hline No & $135515(81.2)$ & $76240(56.3)$ & 1 \\
\hline Yes & $31306(18.8)$ & $11953(38.2)$ & $0.58(0.57-0.60)^{*}$ \\
\hline${ }^{*} p<0.01$ & & & \\
\hline
\end{tabular}

OR 0.58 ; 95\% CI 0.57 - 0.60). There were also significant differences in rates of antibiotic prescriptions by sex and age group. More males than females were prescribed antibiotics, and patients aged $>65$ years were less likely to be prescribed antibiotics than younger patients (OR 0.41, 95\% CI 0.39 - 0.43).

Penicillins (27.0\%), cephalosporins (5.7\%) and other beta-lactams were the most commonly prescribed antibiotics (Table 3 ). Overall, almost $72 \%$ of prescriptions were for these antibiotics.

\section{Discussion}

Based on the study findings, health insurance-linked general practitioners prescribed antibiotics in just over half of the acute bronchitis events that presented to them. While prescribing antibiotics for acute bronchitis events of a bacterial nature may be justified if a patient is at high risk of developing complications, the $\mathrm{NICE}^{[6]}$ and SA STG/EML ${ }^{[7]}$ guidelines suggest that antibiotics should not be prescribed for uncomplicated bacterial bronchitis or viral bronchitis, or where the causative agent is unknown. In this study, almost $92 \%$ of acute bronchitis was unknown or unspecified. Use of antibiotics in the viral and unknown/ unspecified events is therefore considered inappropriate.

With regard to age, based on the NICE guidelines, antibiotic use may be justified if the patient is $>65$ years of age and has a chronic illness. ${ }^{[6]}$ Results from this study indicate that after adjusting for all other exploratory factors, patients aged $>65$ years were least likely to receive antibiotics when presenting for treatment of acute bronchitis. Similarly, with regard to medical status, both the NICE ${ }^{[6]}$ and $\mathrm{SA}^{[7]}$ guidelines broadly recommend that use of antibiotics in the treatment of acute bronchitis be limited to patients with chronic illnesses. The limitations of the data used for this study did not allow for the identification of chronically ill individuals as defined by

Table 3. Type of antibiotics prescribed by type of acute bronchitis

\begin{tabular}{|c|c|c|c|c|c|}
\hline \multirow[b]{2}{*}{ Mechanism of action } & \multirow[b]{2}{*}{ Type of antibiotic } & \multicolumn{4}{|c|}{ Acute bronchitis type } \\
\hline & & $\begin{array}{l}\text { Unknown/ } \\
\text { unspecified, } n(\%)\end{array}$ & $\begin{array}{l}\text { Bacterial, } \\
n(\%)\end{array}$ & $\begin{array}{l}\text { Viral, } \\
n(\%)\end{array}$ & $\begin{array}{l}\text { Total, } \\
N(\%)\end{array}$ \\
\hline Cell wall synthesis inhibitors & $\begin{array}{l}\text { Cephalosporins, penicillins, other } \\
\text { beta-lactams }\end{array}$ & $57342(71.0)$ & $3892(76.0)$ & $1852(78.5)$ & $63086(71.5)$ \\
\hline Protein synthesis inhibitors & Macrolides, tetracyclines & $8858(11.0)$ & $579(11.3)$ & $179(7.6)$ & $9616(10.9)$ \\
\hline DNA synthesis inhibitors & Quinolones & $3869(4.8)$ & $224(4.4)$ & $140(5.9)$ & $4233(4.8)$ \\
\hline Folic acid inhibitors & Sulphonamides and combinations & $1220(1.5)$ & $28(0.5)$ & $70(3.0)$ & $1318(1.5)$ \\
\hline Other combinations & - & $9425(11.7)$ & $396(7.7)$ & $119(5.0)$ & $9940(11.3)$ \\
\hline
\end{tabular}


both the guidelines. Instead, individuals with asthma, cardiovascular diseases, diabetes mellitus or HIV were used as a crude proxy. The sample for HIV-positive patients was too small for a separate analysis. After adjusting for all other exploratory factors, chronically ill individuals, as defined above, were significantly less likely to be prescribed antibiotics than non-chronically ill individuals. Data collected for this study did not allow us to explain the lower rates of antibiotic prescription for the elderly and medically compromised patients. It is possible that older patients and those with chronic illnesses were already on numerous medications, and practitioners were more cautious in adding to this medication intake; however, this theory needs to be explored further using qualitative methods.

Cephalosporins were the second most common beta-lactam prescribed. Neither the $\mathrm{NICE}^{[6]}$ or $\mathrm{SA}^{[7]}$ guidelines recommend cephalosporins in the treatment of acute bronchitis. Further studies need to be conducted to ascertain the use of cephalosporins to treat the condition.

Findings of this study suggest that compliance with evidenceinformed clinical guidelines for the use of antibiotics to treat acute bronchitis is generally poor among general medical practitioners in SA. Reasons for the poor compliance may be related to concerns about maintaining the doctor-patient relationship, patient expectations, and the fact that general practitioners are 'just used to prescribing antibiotics, ${ }^{[3]}$ as found in other settings. There is therefore a need for practitioners to discuss the nature of the condition, i.e. that it is self-limiting but symptoms may persist for about 3 weeks, and that antibiotics are unlikely to be effective or substantially reduce the time to recovery ${ }^{[14]}$ As recommended by the NICE guidelines, ${ }^{[6]}$ the practitioner should also consider a delayed antibiotic prescription. Practitioners may also consider rapid tests such as $\mathrm{C}$-reactive protein (CRP) rapid testing, as CRP testing has been shown to potentially reduce prescribing of antibiotics for patients with acute respiratory tract infections. ${ }^{[15]}$ Research shows that antibiotic prescription is lower when these tests are used to make a decision for prescribing antibiotics. ${ }^{[3]}$

Poor compliance of general practitioners with guidelines in the use of antibiotics for the treatment of acute bronchitis as found in this study raises concerns at two levels. Firstly, it raises questions regarding the appropriateness of antibiotic use in the treatment of other acute respiratory tract infections (ARTIs). Many studies have shown that there is little or no benefit in treating predominantly viral ARTIs with antibiotics. ${ }^{[3]}$ Despite the evidence, the use of antibiotics to treat acute upper respiratory tract conditions remains common. Secondly, studies elsewhere have attributed increasing antimicrobial resistance to inappropriate use of antibiotics for selflimiting conditions, ${ }^{[16]}$ and the findings of this study raise concerns regarding the contribution inappropriate antibiotic use is making towards the growing public health concern of antibiotic resistance.

\section{Study limitations}

This study has a number of limitations. The ICD-10 codes as submitted by general practitioners were key to the analyses carried out for this study, yet there are questions around the accuracy and consistency of this coding. There is also some ambiguity regarding which ICD-10 code should be used, e.g. the Department of Health lists J20 as acute bronchitis and J20.0 as acute bronchitis caused by Mycoplasma pneumoniae. ${ }^{[7]}$ Another limitation is that we assumed that if the acute bronchitis consultation and antibiotic provision were on the same day, they were directly related. Also, members of the scheme who opted to pay cash for treatment were not captured in the analyses. Furthermore, the SA STG/EML guidelines ${ }^{[7]}$ give HIV as a chronic condition for which patients with acute bronchitis should be prescribed antibiotics. However, we were not able to determine from our sample how many patients were co-infected with HIV (and hence used 'presence of a chronic condition' as an exploratory factor). Despite these limitations, we believe that the study findings are valuable in terms of prescribing of antibiotics for acute bronchitis.

\section{Conclusions}

Findings of this exploratory study point to the need for further research and work in the use of antibiotics for acute bronchitis. Further research, including qualitative methods to probe reasons for the use of antibiotics in treating acute bronchitis, will guide local understanding of the extent of practitioners' non-compliance across all sectors in SA. Qualitative study approaches would be valuable in exploring the reasons for poor compliance and identifying contextspecific approaches to improve the implementation and uptake of antibiotic prescribing guidelines. Without action, we may well be faced with a reality in the near future where we are longer able to use antibiotics to treat common infections.

\footnotetext{
1. Editorial. Antibiotic resistance: Long-term solutions require action now. Lancet Infect Dis 2013;13(12):995. http://dx.doi.org/10.1016/S1473-3099(13)70290-1

Center for Disease Dynamics, Economics \& Policy. State of the World's Antibiotics, 2015. Washington, DC: CDDEP, 2015.

3. Llor C, Bjerrum L. Antibiotic prescribing for acute bronchitis. Expert Rev Anti Infect Ther 2016;14(7):633-642. http://dx.doi.org/10.1080/14787210.2016.1193435

4. Smith SM, Fahey T, Smucny J, et al. Antibiotics for acute bronchitis. Cochrane Database Syst Rev 2014, Issue 3. Art. No.: CD000245. http://dx.doi.org/10.1002/14651858.CD000245.pub3

5. Albert RH. Diagnosis and treatment of acute bronchitis. Am Fam Physician 2010:82(11):1345-1350.

5. Albert RH. Diagnosis and treatment of acute bronchitis. Am Fam Physician 2010;82(11):1345-1350.
6. National Institute for Health and Care Excellence. Respiratory Tract Infections (Self-limiting) Prescribing Antibiotics. London: NICE, 2008.

7. National Department of Health, South Africa. Standard Treatment Guidelines and Essential Medicines List for South Africa - Primary Health Care Level. Pretoria: NDoH, 2014

8. Woodhead M, Blasi F, Ewig S, et al. Guidelines for the management of adult lower respiratory tract infections - full version. Clin Microbiol Infect 2011;17(Suppl 6):E1-E59. http://dx.doi.org/10.1111/ j.1469-0691.2011.03672.x

9. Barnett ML, Linder JA. Antibiotic prescribing for adults with acute bronchitis in the United States, 1996-2010. JAMA 2014;311(19):2020-2022. http://dx.doi.org/10.1001/jama.2013.286141

10. Grijalva CG, Nuorti JP, Griffin MR. Antibiotic prescription rates for acute respiratory tract infections in US ambulatory settings. JAMA 2009;302(7):758-766. http://dx.doi.org/10.1001/jama.2009.1163

11. Harris AM, Hicks LA, Qaseem A, et al. Appropriate antibiotic use for acute respiratory tract infection in adults: Advice for high-value care from the American College of Physicians and the Centers for
in Disease Control and Prevention. Ann Intern Med 2016;164(6):425-434. http://dx.doi.org/10.7326/ Disease Control and Prevention. Ann Intern Med 2016;164(6):425-434. http://dx.doi.org/10.7326/ M15-1840

12. Woodhead M, Blasi F, Ewig S, et al. Guidelines for the management of adult lower respiratory tract infections - summary. Clin Microbiol Infect 2011;17(Suppl 6):1-24. http://dx.doi.org/10.1111/j.14690691.2011.03602.x

13. Ivanovska V, Hek K, Mantel Teeuwisse AK, et al. Antibiotic prescribing for children in primary care and adherence to treatment guidelines. J Antimicrob Chemother 2016;71(6):1707-1714. http://dx.doi. org/10.1093/jac/dkw030

14. Brink AJ, Cotton MF, Feldman C, Geffen L, Hendson W. Guideline for the management of upper respiratory tract infections. 2004. https://scholar.sun.ac.za/handle/10019.1/7133 (accessed 29 April 2016).

15. Andreeva E, Melbye $\mathrm{H}$. Usefulness of C-reactive protein testing in acute cough/respiratory tract infection: An open cluster-randomized clinical trial with C-reactive protein testing in the intervention group. BMC Fam Pract 2014;15:80. http://dx.doi.org/10.1186/1471-2296-15-80
}

Accepted 14 October 2016 